\title{
La ficción de Kant en la tercera Crítica $^{1}$
}

\author{
Kant's fiction in the third Critique
}

Edgardo Tillería Aqueveque ${ }^{2}$

Universidad Tecnológica de Chile INACAP

Recepción: 20 de octubre del 2020

Evaluación: 21 de enero del 2021

Aceptación: 30 de enero del 2021

1 El presente artículo corresponde a una investigación patrocinada por el Área de Tecnologías de la Información \& Ciberseguridad de la sede Temuco de la Universidad Tecnológica de Chile INACAP.

2 Doctor en Filosofía (Filosofía y Humanidades) por la Universidad Tecnológica de Chile INACAP. Correo electrónico: leopoldo.tilleria@inacapmail.cl

Tillería, E. (2021). La ficción de Kant en la tercera Crítica. 


\title{
Resumen
}

Se sugiere la idea de una tercera Crítica fundamentada en la ficción. Para ello se conjetura, por un lado, que Kant recurre a la analogía del como si a fin de forzar la relación epistémico-estética del sujeto con una presunta finalidad de las cosas, y, por otro, que incrusta la figura del genio para resolver la antinomia de un arte bello conforme a fin, pero sujeto a reglas. Dicha ficción reflejaría la zozobra de un Kant que intenta mostrar una estructura racional formal unitaria, pero que consta de varios usos irreconciliables.

Palabras claves: como si, ficción, genio, Kant, tercera Crítica.

\begin{abstract}
The idea of a third Critique based on fiction is suggested. For this, it is conjectured, on the one hand, that Kant resorts to the analogy of the as if in order to force the epistemic-aesthetic relationship of the subject with a presumed purpose of things, and, on the other, that he embeds the figure of the genius to solve the antinomy of a beautiful art according to purpose, but subject to rules. Said fiction would reflect the anxiety of a Kant who tries to show a unitary formal rational structure, but which consists of several irreconcilable uses.
\end{abstract}

Keywords: as if, fiction, genius, Kant, third Critique. 


\section{Introducción}

Una parte importante de comentaristas de Kant plantea que la Crítica del juicio representaría algo así como el cierre de su proyecto epistemológico, prefigurado en un Kant preocupado por descubrir el principio que exige la adaptabilidad de la naturaleza al propósito de nuestro entendimiento. Para Körner (1977), por ejemplo, la Crítica del juicio, como un todo, mantiene en su integridad la concepción mecanicista de la naturaleza explicada en la primera Crítica, examinando la función de los conceptos de propositividad, propósito y causa final, y su aplicabilidad a los juicios estéticos y científicos. Igual percepción tiene Martynova (2020), para quien lo central en la Crítica del juicio es pensar en la naturaleza a través del principio de intencionalidad: "Comprobando los datos de la experiencia, la razón encuentra solo una manera de juzgar adecuadamente a los organismos. Asume que son propósitos naturales y tienen normatividad y espontaneidad como una persona" (p. 43) ${ }^{3}$.

Eso en el papel. En los hechos, son más los interrogantes y paradojas que resultan de una revisión detenida de la Crítica del juicio. Para Johnson (2011), por ejemplo, la tercera Crítica justificaría la posibilidad de considerar el arte abyecto como una forma legítima de arte (p. 4). En la esfera de la génesis del texto se halla la interpretación que ve en la Crítica del juicio una no declarada cuarta Critica; tesis que desarrolla sugerentemente Reinhard Brandt en su trabajo La cuarta Crítica de Kant (2006), en el que asigna a la obra de 1790 la función principal de reconstrucción del sistema crítico. Desde la vereda de la deconstrucción, Derrida dará un golpe de timón respecto de recepciones más tradicionales y pondrá acento en la idea de inaccesibilidad. Su recepción de la tercera Crítica, cuando no de Kant mismo, se funda en lo que pudiéramos llamar una teoría del marco. El filósofo francés de origen argelino accede a la deconstrucción de la Crítica del juicio mediante la constatación de que este marco es imposible de completar dado el estatus de la propia Crítica del juicio en el sistema de Kant: "Este sistema de filosofía pura (el que debe comprender en sí mismo la crítica) es lo que Kant llama la metafísica (...) Solamente la crítica puede tener actualmente un programa posible" (Derrida, 2001, p. 51).

\footnotetext{
3 "In checking the data of experience, reason finds only one way to adequately judge organisms. It assumes that they are natural purposes and have normativity and spontaneity like a person".
} 
Más lapidaria es la interpretación de Dickie, quien sencillamente ve en la Crítica del juicio una obra armada al revés, lo que implica que la crítica estética debería ser su última parte, y la crítica teleológica, la primera. Para el filósofo estadounidense la Crítica del juicio es una obra eminentemente teleológica, puesto que Kant desarrolla su estética: "1) haciendo derivar conceptos centrales de su teoría del gusto de su teleología y 2) elaborando versiones de lo que considera que son las características estándar de la teoría del gusto (recogidas de pensadores como Hutcheson y Burke) dentro de su propio sistema teleológico" (Dickie, 2003, p. 165). De este modo, el propósito principal de la Crítica del juicio consistiría en justificar nuestra creencia en un mundo teleológico no experimentado, que circunda y sustenta al mundo epistemológico a través del cual nos asomamos con anhelo. Por último, refrendar la poco ortodoxa opinión de Grondin, para quien se debe ligar toda la Crítica del juicio con la sistemática de la filosofía práctica. Señala el filósofo canadiense: "En la primera sección, lo Bello aparece claramente como un símbolo de la moralidad, y la teleología siempre intenta sorprender el substrato suprasensible de la naturaleza, substrato que viene a confrontarnos con nuestro destino moral" (Grondin, 2000, p. 82).

En este polifónico escenario, no se trata solo de sumar una nueva lectura del enigmático texto del filósofo regiomontano, sino de intentar profundizar aún más en una interpretación hasta ahora olvidada, que considera el papel decisivo -aunque no explícito- de la ficción en el sentir del sujeto. Dicha conjetura pone el acento en que en la Crítica del juicio la facultad de juzgar no desarrollaría una relación precisamente "doctrinaria" respecto del ánimo (Gemüt); es decir, que su conexión con el sentimiento de placer y displacer se fundaría cardinalmente en lo que por ahora llamaré recursos de ficción, en especial la analogía del como si y la facultad del genio.

Zanjando la cuestión terminológica, entenderé la noción de ficción en el sentido en que originalmente la expone Platón en dos de sus diálogos: como invención (Timeo) y como fingimiento (República). Lo que quiero decir es que, si entiendo bien a Kant, el concepto de ficción presentado en la Crítica del juicio varía según el argumento que se quiera exponer. De esta laya, la noción de ficción que subyace en torno al genio artístico parece ser justamente la de una rotunda invención ${ }^{4}$, teniendo en cuenta -al menos si seguimos a

\footnotetext{
${ }^{4}$ La idea de ficción como invención -o creación- que aparece en el Timeo, está íntimamente conectada con esa especie de cosmología que el propio Timeo relata a Critias: "Este resto lo llevó a cabo estampando una impresión en la naturaleza de la copia. Pensó, pues, que este mundo debía
} 
la letra el § 46- que Kant nunca explica cómo surge esta extraña facultad ni menos cómo es que logra transformarse en naturaleza en su prodigiosa tarea de "dar la regla al arte". Parece ser, entonces, la acción propia de un demiurgo. En cambio, cuando el filósofo se refiere a la analogía del como si, lo hace poniendo en juego una idea de ficción que ya no tiene que ver con la invención de ninguna facultad estética o teleológica, sino más bien con la figura de hacer "como que algo es", no siéndolo finalmente. Sería, pues, más propio hablar aquí de una cierta heurística de la ficción y, por tanto, de una ficción como falseamiento ${ }^{5}$. Al respecto, Costa (2018) sugiere que el tratamiento que Platón hace de la ficción en la República sería de dos clases: como falsedad inconsciente y como falsedad consciente. La que me interesa conectar con la analogía del como si es precisamente la segunda, en términos de que mediante ella "se afirma algo a sabiendas de que eso no es, en rigor, verdad sino algo que eventualmente puede 'asimilarse a la verdad' y llegar a convertirse así en 'un remedio útil' aunque, obviamente, el resultado de la asimilación no pueda garantizarse a priori” (p. 24).

En la primera sección abordaré algunas interpretaciones de la tercera Crítica que parecieran ser de las más influyentes actualmente. Luego, me detendré en los elementos claves del dictum kantiano que fundamentarían la tesis de una Crítica del juicio subordinada a la idea de ficción. Las conclusiones intentarán mostrar en qué sentido esta ficción refleja la zozobra de un Kant enfrentado a un uso problemático de la razón.

tener en sí especies de una cualidad tal y en tanta cantidad como el intelecto ve que hay en el ser viviente ideal (...) Hizo la mayor parte de la forma de lo divino de fuego para que fuera el género más bello y más luminoso para la vista, y lo construyó perfectamente circular, semejante al universo" (39e-40a). Sin entrar en detalles, es bastante sugerente la analogía que se puede hacer entre la figura del genio kantiano y la de los dioses menores o inferiores tratada en el diálogo.

5 Lo cardinal de este diálogo entre Sócrates y Glaucón parece ser la convicción de Platón de que prácticamente todas las cosas del universo pueden ser creadas a semejanza de las esencias, pero, sin embargo, "solo de cierto modo": "¿No te percatas de que tú también eres capaz de hacer todas estas cosas de un cierto modo? - ¿Y cuál es este modo? -No es difícil, sino que es hecho por artesanos rápidamente y en todas partes; inclusive con el máximo de rapidez, si quieres tomar un espejo y hacerlo girar hacia todos lados: pronto harás el sol y lo que hay en el cielo, pronto la tierra, pronto a ti mismo y a todos los animales, plantas y artefactos, y todas las cosas de que acabo de hablar. -Sí, en su apariencia, pero no en lo que son verdaderamente. -Bien; y vienes en ayuda del argumento en el momento requerido. Uno de estos artesanos es el pintor, creo. ¿O no?" (República X, 596d-596e). Si bien en principio es el artista el llamado a crear este universo de "cierto modo", finalmente cualquier mortal (Glaucón, el primero) puede re-crear el mundo haciendo girar el espejo.

Tillería, E. (2021). La ficción de Kant en la tercera Crítica. 


\section{Recepciones contemporáneas de la tercera Crítica}

Alexis Philonenko concibe la Crítica del juicio como una completa fenomenología del mundo. Dicho brevemente: sugiere la existencia de dos campos noemáticos generales en el texto de Kant, que se insertarían entre el campo del sujeto y el del fenómeno en general. A partir de aquí Philonenko designa los cuatro subcampos noemáticos que completan la unidad de la filosofía trascendental. Estos subcampos son el de lo bello y el de lo sublime, en la crítica de la facultad de juzgar estética, y el de una teoría de la organización y el de una teoría de la vida, en la crítica de la facultad de juzgar teleológica (1998, p. 44). Según el filósofo francés, la arquitectónica de la Crítica del juicio se condensaría, entonces, en la presentación de un fenómeno (primera Crítica), perteneciente a un sistema racional (crítica de la facultad de juzgar teleológica), que consideramos bello (crítica de la facultad de juzgar estética) como un ser razonable (segunda Crítica).

Para el francés la Crítica del juicio se divide en dos momentos: uno reservado a la estética y otro a la teleología. Cada uno corresponde a rangos de investigación trascendental que, aunque se iluminan entre sí, son sin embargo campos noemáticos distintos y, por lo mismo, puede extraerse de ellos solo un concepto distinto de la cosa en sí (p. 47). De manera que la arquitectónica de la Crítica del juicio se duplica en profundidad: por un lado, se hallaría la esencia arquitectónica de la reflexión trascendental que vincula los campos noemáticos y, por otro, la arquitectónica interna del conocimiento a través de la cual el mundo se revela como inteligible. Dicha arquitectónica, en general, se puede asimilar a la razón filosófica; el verdadero sujeto de la filosofía. Es propiamente lo que se llama filosofía trascendental. La arquitectónica revela aquí su límite fundamental: solo puede apropiarse del campo noemático en la medida en que esté inscrita en una historia natural. Mas la historia del arte escapa por completo de las manos de Kant, acota Philonenko, revelando en cierto modo los problemas metodológicos de Kant a la hora de presentar una filosofía del arte: "Kant no tenía la brillante intuición de un museo imaginario y, sin embargo, la lógica de su sistema lo llevó a ver el hecho y la inteligibilidad unidos al menos como un Ideal, aunque de ninguna manera como un objetivo real" $(1988, \text { p. } 51)^{6}$.

6 "Kant n'a pas eu l'intuition géniale d'un musée imaginaire et pourtant la logique de son système le
conduisait à voir s'unir fait et intelligibilité au moins comme Idéal, nullement comme visée réelle". 
Por su parte, Daniel Dumouchel verá la génesis de la tercera Crítica en la dimensión estética; una dimensión que se constituirá en una bisagra entre el Iluminismo y el Romanticismo. Tal idea no deja de ser un problema central en la Crítica del juicio. Llamaremos a este "conflicto" el primero de la serie. El segundo se refiere a la trayectoria que ha seguido el proyecto estético de Kant entre 1787 y 1790: "El estudio de la génesis concreta de la Crítica de la facultad de juzgar nos enseña, por ejemplo, que fue primero en la forma de una "Crítica del gusto» que Kant, hacia 1787, quiso introducir lo que llamamos «estética» en la filosofía crítica" (Dumouchel, 1998, p. 18) 7 . Esta incrustación, a medio camino de una dirección estética en la Crítica del juicio, supone necesariamente un cambio de rumbo hacia una perspectiva teleológica general, dominada por la nueva figura de la facultad de juzgar reflexionante (p. 19).

Dicha heurística, que radica en la finalidad natural, es lo que Dumouchel reconocerá como lectura teleológico-sistémica de la estética kantiana, “(...) que paradójicamente abre la brecha a una interpretación romántica e idealista de la estética filosófica de Kant, y proporciona el material para el fundamento filosófico de las filosofías del arte posteriores, en la medida en que reaviva la analogía entre belleza y finalidad natural" (p. 23) ${ }^{8}$. El peso trascendental de la Crítica del juicio recaería en una naturaleza, como quien dice, sublimada mediante el principio de finalidad. Se trata de un mundo artificialmente esquematizado, aunque provisto de todos los privilegios de una naturaleza organizada. De este modo, en la década del setenta del siglo XVIII la teoría precrítica del genio unirá el gusto y la facultad de juzgar como las facultades limitativas que compondrán el genio, junto con las facultades productivas de la sensación y el espíritu (p. 25). Se añade a esto el "choque" estético entre los enfoques racionalista, físico-teológico y naturalista:

De hecho, la idea misma de una conexión entre la reflexión estética y el concepto de finalidad (en el sentido amplio) está fuertemente sugerida por la época, por la tradición racionalista de la estética de la perfección, primero, pero también por la persistencia de los esquemas estéticos heredados de

\footnotetext{
7 "L'étude de la genèse concrète de la Critique de la faculté de juger nous apprend par exemple que c'est d'abord sous la forme d'une «Critique du goût» que Kant, vers 1787, a souhaité introduire ce que nous appelons l'«esthétique» dans la philosophie critique".

8 “(...) qui ouvre paradoxalement la brèche à une interprétation romantique et idéaliste de l'esthétique philosophique de Kant, et fournit les matériaux pour la fondation philosophique des philosophies de l'art ultérieures, dans la mesure où elle ranime l'analogie entre la beauté et la finalité naturelle".
} 
la físico-teología de la primera mitad del siglo, así como por la creciente asociación, en la Alemania de los años 80, entre la belleza artística y el organismo natural, como los escritos de Herder, Moritz y luego Goethe lo testimonian (p. 28) .

La tercera interpretación es la de Antonio Marques. Para el filósofo portugués en la Crítica del juicio Kant aparenta hacer patente una diferencia trascendental: la de la reflexión estética versus la reflexión teleológica. Esta última -a diferencia de la primera, que carecería de cualquier tipo de interés- está caracterizada por un interés cognitivo. Tal sería, por así decir, la versión "oficial". Sin embargo, Marques (1998) sugiere que en realidad ambos modos de reflexión -el estético y el teleológico- tendrían en principio un componente cognitivo original. En efecto, piensa Marques, la idea cardinal de la Crítica del juicio acerca de la constitución de una experiencia coherente de la naturaleza, vale decir, de un interés en la sistematización de la naturaleza en géneros, especies y subespecies, tiene una característica principalmente teleológica y no estética, “(...) aunque en la sección VI de la Introducción publicada curiosamente se afirma la asociación del placer a la tarea de sistematización y a la ampliación del conocimiento mediante la investigación de la naturaleza" (p. 221)

Podríamos describir la comprensión de la Crítica del juicio por parte de Marques, y en particular sobre la reflexión estética, como abiertamente epistémica. De hecho, recurre como uno de sus argumentos centrales a la consabida prioridad del juicio sobre el placer, que Kant presenta en el $\S 9$. Sobre esta condición, Marques plantea que la reflexión estética finalmente no es más que una operación intelectual de la que uno no es necesariamente consciente: "El juicio estético equivaldría entonces a una triple síntesis ya presentada en la Crítica de la razón pura, pero sin la última síntesis que corresponde al reconocimiento en el concepto" (p. 222) ${ }^{11}$. Este autor sugiere

\footnotetext{
9 "En fait, l'idée même d'une liaison entre la réflexion esthétique et le concept de finalité (au sens large) est fortement suggérée par l'époque, par la tradition rationaliste de l'esthétique de la perfection, d'abord, mais également par la persistance des schèmes esthétiques hérités de la physico-théologie de la première moitié du siècle, de même que par l'association grandissante, dans l'Allemagne des années quatre-vingt, entre la beauté artistique et l'organisme naturel, comme en témoignent les écrits de Herder, de Moritz, puis de Goethe".

10 “(...) although section VI of the published Introduction curiously states the association of pleasure to the task of systematization and to the broadening of knowledge by the researcher of nature".

11 "The aesthetic judgment would then be equivalent to a triple synthesis already presented in the Critique of Pure Reason, but without the last synthesis that corresponds to the recognition in the concept".
} 
que la estructura "mental" que determina que la naturaleza sea pensada como la génesis de nuestra reflexión estética y teleológica, es precisamente la analogía del como si, puesto que no experimentaríamos placer en la naturaleza si la representáramos como un mero aglomerado mecánico de fuerzas brutas. Observa Marques: "Sería conveniente, además, recordar que el principio específico de todo juicio reflexivo (estético o teleológico) es el de una técnica de la naturaleza, que nos hace considerar la naturaleza como si estuviera organizada según un principio inteligente que solo podemos representar por analogía con nuestro entendimiento" (p. 226) ${ }^{12}$.

Por tanto, el interés que podemos rastrear en la base de la reflexión estética o teleológica sería primordial e inmediatamente cognitivo, puesto que lo que está en juego es en realidad la inadecuación entre la forma percibida y los conceptos del entendimiento. De hecho, la facultad de juzgar confronta esa forma con cualquiera de las categorías de la naturaleza o leyes universales y se da cuenta de que su origen no puede residir en ellas (p. 220).

\section{La ficción del como si}

Como ya anticipé, quisiera sugerir que la tercera Crítica contiene en varios pasajes argumentos decisivos que no pueden explicarse sino desde el campo de la ficción. Parafraseando a Álvarez (2017), podría decirse que el carácter técnico de la facultad de juzgar, en cuanto capacidad de discernimiento y de reflexión, resulta insuficiente para explicar el rendimiento tanto del juicio estético como del teleológico. Si esto es así, el cierre completo de la filosofía de Kant pendería, stricto sensu, no del uso de la razón en su función trascendental, sino propiamente de la ficción.

La ficción del como si se presenta ya en el mismo epicentro de la primera Crítica $^{13}$. Kant la considera indispensable para siquiera empezar su crítica de

\footnotetext{
12 "It would, furthermore, be convenient to remember that the principle which is specific to every reflexive judgment (either aesthetic or teleological) is that of a technique of nature, which makes us consider nature as if it were organized according to an intelligent principle which we can only represent by analogy with our understanding".

${ }^{13}$ Aquí se ubica, aunque en un terreno distinto a la Crítica del juicio, como es el del idealismo trascendental de la primera Crítica, la analogía ficcional presentada por Hans Vaihinger en Die Philosophie des Als $\mathrm{Ob}$ de 1911, en relación a la posibilidad de que la cosa en sí pueda afectar al sujeto en la investigación kantiana acerca de lo real. Como afirma Pringe (2013): "Tal objeto trascendente adquiere, en términos de Vaihinger, el carácter de ficción, ya que satisface las cuatro características que Vaihinger atribuye a toda representación ficcional: su carácter contradictorio, su utilidad, el hecho de que seamos conscientes de que con ella no nos representamos ningún objeto real y, finalmente, el carácter provisorio de tal representación” (p. 5).
}

Tillería, E. (2021). La ficción de Kant en la tercera Crítica. 
la metafísica tradicional, en cuanto supone una necesaria salvedad a la hora de poder sostener la deducción trascendental de su epistemología. En efecto, leemos en el "Apéndice a la Dialéctica Trascendental": "Por ello se dice, por ejemplo, que hay que considerar las cosas del mundo como si recibieran su existencia de una inteligencia suprema. De esta forma, la idea no es en realidad más que un concepto heurístico, no ostensivo" (KrV, A 671). Escribe Kant más adelante, en una suerte de justificación del uso empírico de la razón hacia su máxima extensión, bajo el supuesto de que los objetos mismos procedieran de un arquetipo de toda razón:

Finalmente, tenemos que considerar (en relación con la teología) todo aquello que sólo puede formar parte del contexto de la experiencia posible como si ésta constituyera una unidad absoluta, pero enteramente dependiente y siempre condicionada dentro del mundo sensible y, al mismo tiempo, como si el conjunto de todos los fenómenos (el mundo sensible mismo) tuviera un único fundamento supremo y omnisuficiente fuera de cuanto abarca, es decir, una razón que fuese, por así decirlo, independiente, originaria y creadora (A 672).

Y en un sentido abiertamente teleológico, subrayará:

De ello se desprende, pues, que (la idea del orden del mundo como si dimanara del propósito de una razón suprema) no es más que un principio regulador de la razón, destinado a llegar a la máxima unidad sistemática mediante la idea de causalidad final de la última causa, como si ésta fuese, en cuanto inteligencia suprema, la causa de todo conforme al más sabio propósito (A 688).

Es decir, se trata de principios que se basan ellos mismos en conceptos y no en intuiciones. En otras palabras, el terreno de la ficción, del cambio de registro de un término por otro más efectivo o ajustado a la jurisdicción de la crítica, surge desde temprano en la meditación del filósofo como esclarecimiento metodológico. En cierto modo pudiera hablarse con cierta propiedad de una performatividad de la ficción.

La dirección que toma el como si en la Crítica del juicio apunta a su propia arquitectónica. Constituye literalmente, y de esto con seguridad se haya dado cuenta Kant con posterioridad a la conocida carta a Reinhold de 1787 que anunciaba la fundamentación de una crítica del gusto ${ }^{14}$, un recurso heurístico

\footnotetext{
${ }^{14}$ Escribe Kant (2005): “Esa perspectiva sistemática me llevó a este camino por el que ahora reconozco tres partes de la filosofía, de las cuales cada una tiene sus propios principios a priori,
} 
de la propia facultad de juzgar. Sin la ficción del como si (que presenta a la naturaleza como si estuviera destinada para nuestro enjuiciamiento de lo bello o a la totalidad del mundo natural como si se presentara organizada por un organismo superior), el sentimiento de placer y displacer se desmoronaría en las propias barbas del entendimiento y la razón. Diríamos, entonces, aludiendo a Platón, que esta idea hace posible la re-creación del mundo natural haciendo girar el espejo.

El como si permite con eficacia la conexión entre la crítica de la facultad de juzgar estética y la teleológica. Kant llegará a su formulación en la Crítica del juicio, argumentando que la naturaleza bella o la obra de arte bello no deben ser representadas como objetos de conocimiento. Como conceptualmente no sabemos nada de ellas, nuestra razón debe hacer como si -en su formaparecieran por entero adecuadas a ella, único modo de provocar el sentimiento de placer asociado a lo bello. Leemos en el $\S$ 45: "Ante un producto del arte bello debe hacerse uno consciente de que es arte y no naturaleza; no obstante, la conformidad a fin en la forma de aquél debe parecer tan libre de toda sujeción a reglas arbitrarias como si fuera un producto de la mera naturaleza" (2005, pp. 215-216). Esta especie de "parche" ontológico, que constituye el como si, tal como observa Falgueras (1999), representa "el desarrollo positivo del método escéptico" (p. 120). Es decir, "el als ob viene a ser el complemento metódico positivo de la autolimitación del conocimiento a la experiencia sensible" (pp. 120-121). Kant ha renunciado, como resultado de la primera Crítica, a la idea de una sistematicidad en la naturaleza deducida por la vía teórica. Sin embargo, en la Crítica del juicio llegará a esta idea por la problemática vía de la heurística del principio de finalidad, llamado también 'principio de conformidad formal a fines de la naturaleza' en otros lugares de la Crítica del juicio.

En el caso de la finalidad subjetiva, cuyo cometido es la posibilidad de la reflexión estética, se trata en realidad de que en cuanto finalidad sin fin pueda conectar la síntesis de la imaginación productiva con la unidad provista por la facultad de juzgar reflexionante. En palabras del propio Kant:

que se pueden enumerar, y de esta manera determinar el alcance del conocimiento posible filosofía teórica, teleología y filosofía práctica-; de las cuales la segunda aparece evidentemente como la más pobre en fundamentos de determinación a priori. Espero terminar esta obra bajo el título de la «Crítica del gusto» hacia Pascua en manuscrito, aunque la impresión tardará más" (p. 185). 
La conciencia de la conformidad a fin puramente formal en el juego de las fuerzas de conocimiento del sujeto (...) es el placer mismo, porque contiene un fundamento de determinación de la actividad del sujeto en vista de la vivificación de sus fuerzas de conocimiento $\mathrm{y}$, por tanto, una causalidad interna (...) con vistas al conocimiento en general, mas sin estar restringida a un conocimiento determinado, $\mathrm{y}$, con ello, contiene una mera forma de conformidad a fin subjetiva de una representación en un juicio estético $(\S 12$, p. 138).

En cambio, en el ámbito de la finalidad objetiva la ficción se desplaza del campo de nuestra relación cognitiva con las formaciones de la naturaleza, al de las relaciones entre ellas mismas y de su propia constitución interna. Se trata de la ficción de la naturaleza como "mecanismo". A diferencia de una explicación de tipo físico-mecánica, fundada en la descripción de los Principios metafísicos de las leyes de la naturaleza y en la deducción trascendental de la primera Crítica, la consideración de la naturaleza como organismo equivale a la idea de un todo como fundamento de la posibilidad de las partes. El camino es un poco más escabroso, pues precisamente la complejidad de esta organicidad de las formas naturales finalizadas requiere de una extraña combinación de analogías que Kant administra con un ojo puesto en la ciencia y el otro en el arte. Detengámonos, por la relevancia que implica esta suerte de ficción técnica, en la efectividad de la analogía 'arte/ organismo' que desarrolla en el $\S 65$ :

Es muy poco lo que se dice de la naturaleza y de su facultad en los productos orgánicos cuando a ésta se la llama un análogo del arte, pues en tal caso se piensa al artista (un ser racional) fuera de ella. Más bien se organiza ella a sí misma, y en cada especie de sus productos orgánicos, por cierto, con arreglo a un mismo ejemplar en (su) conjunto, pero también con desviaciones convenientes, que la autoconservación requiere según las circunstancias (p. 305).

En suma: de lo que se trata con esta idea de hacer como si la naturaleza fuera un organismo creado por alguien externo a nosotros, es simplemente comprender mejor su funcionamiento y "completar" la faena gnoseológica avisada por Kant en sus trabajos anteriores. Este trabajo "completo", como dijimos, es el sistema de la razón. Tal es el motivo por el cual el filósofo de Königsberg llamará a este sistema explicativo "una cosa como propósito natural".

Enseguida veremos cómo la facultad del genio representa probablemente el componente de ficción más extraño de la Crítica del juicio. 


\section{El genio o la ficción de la filosofía del arte}

En pleno corazón de su crítica del arte, Kant entrega esta curiosa definición de genio: "Genio es el talento (don natural), que le da la regla al arte" (§ 46, p. 216). Si nos fijamos bien, el talento y la regla parecen ser lo medular de la definición. Esto no debiera sorprendernos, pues lo que Kant intenta hacer mediante esta figura "nacida" del espíritu es conciliar en la esfera del arte dos tesis consideradas hasta ahora antagónicas en la analítica de lo bello. Primero, que el enjuiciamiento de lo bello carece en su base de fin, o sea, de algún tipo de concepto, y segundo, que todo arte lo es solo en la medida en que haya en él algo que deba ser ejecutado conforme a reglas, es decir, según un cierto procedimiento artístico o, si se quiere ir aún más lejos, por medio de la academia.

El genio, pues, deberá hacer concordar finalidad y regla. Su obra nos parecerá como si estuviera realizada de antemano para un determinado fin, pero sin que seamos capaces de determinar cuál es éste exactamente o, lo que es lo mismo, que no tengamos ningún concepto a la mano para calificar esta finalidad. El filósofo se verá atrapado en su argumentación entre una explicación del genio como excepción, y otra, que lo muestra como un caso paradigmático de su crítica estética, como "una enseñanza metódica según reglas" para otros posibles genios que hayan podido sacar dichas reglas de “aquellos productos del espíritu y de su característica" (§ 49, p. 227). El genio viene entonces a intentar "salvar" el proyecto de una filosofía del arte como parte necesaria de la teoría estética de Kant. Sin embargo, este proyecto queda trunco justamente por el titubeo de Kant entre una metafísica del arte y una estética filosófica como núcleo de su tercera Crítica.

La rara incrustación del genio como facultad anímica del artista ha dado pie a un interminable desacuerdo entre los comentaristas de Kant. Se ha dicho -canónicamente- que el genio es en realidad el propio artista (Besançon, 2006), la reconciliación entre libertad y naturaleza (Ertene, 2012) o incluso un nexo entre belleza y arte (Lories, 1998). Empero, la explicación que da Kant en la Crítica del juicio acerca de la "materia" del genio es a todas luces insuficiente. ¿Es el mismo artista? ¿Un talento aleatorio dado por la naturaleza humana o por alguna otra? ¿El resultado superlativo del despliegue de la imaginación en su libre juego con el conocimiento? ¿O el producto académico de esas inexplicadas reglas que son conferidas al arte y que, de un modo u otro, pudieran replicarse mediante el concurso académico? (recordemos que en sus investigaciones tempranas Kant se preguntaba si 
era necesario también genio en las producciones matemáticas y filosóficas). Como bien reflexiona Desmond (1998, p. 613): "Una vez más, al final, la Ilustración debe gobernar el Romanticismo, y el potencial desenfreno del genio debe someterse a reglas" ${ }^{\prime 15}$. Besançon (2006), a su vez, ha planteado muy certeramente la conjetura del genio como espíritu:

Kant ha legado a todo artista posterior dos conceptos fatales. El primero es el de genialidad. La palabra ya existía: significaba una excelencia en el oficio, una facilidad extraordinaria para obedecer a las reglas del arte. El genio kantiano, no obedece a las normas, las da. Es una especie de médium en quien reposan las leyes de la naturaleza. Es supraconsciente. Es, igualmente, inconsciente, ya que el genio no sabe realmente ni lo que hace, ni cómo lo hace. La genialidad ni se aprende, ni se enseña. La enseñanza del oficio es, por lo tanto, inútil; la escuela no es más que un lugar donde se construye la explosión o no del genio. La originalidad absoluta se convierte en la condición del arte (p. 220).

Al recurrir a la idea de genio para fundamentar la tesis del arte bello (incluida la no menos oscura definición del genio como facultad de ideas estéticas), lo que termina haciendo Kant es - permítaseme la analogía- destapar una vieja botella y frotarla de tal forma que el genio liberado se conceda a sí mismo las facultades del juicio estético presentadas en la analítica. Sugiere Lories (1998):

El conflicto surge del hecho de que la libertad creativa del genio saca sus Ideas estéticas de la orientación respecto de las Ideas racionales. En cuyo caso, sus inventos estéticos son puras fantasías indivisibles -la universalidad ya no está garantizada, puesto que el punto de referencia de la razón ya no está allí. El rico material proporcionado por el genio ya no cumple las condiciones que permiten compartirlo universalmente, y el gusto funciona en vano (p. 589) ${ }^{16}$.

Es decir: el genio intenta agrupar la totalidad de las cualidades estéticas asociadas al juicio de gusto, pero, sin embargo, es una facultad... ipráctica!

\footnotetext{
15 "Again in the end Enlighttenment must rule Romanticism, and the potential wildness of genius be subjected to rules".

16 "Soit le conflit naît de ce que la liberté créatrice du génie fait sortir ses Idées esthétiques de l'orientation vers les Idées rationnelles. Auquel cas, ses inventions esthétiques sont de pures fantaisies impartageables-universalité n'est plus garantie, puisque le repère de la raison n'est plus là. La riche matière fournie par le génie ne remplit plus les conditions qui rendent possible son partage universel et le goût travaille en vain".
} 
De modo que la ficción que supone la "aparición" del genio en la mitad de la teoría del arte de la Crítica del juicio parece consistir en que se trata de un poder para producir objetos. Para hacerlo todo aún más confuso, agregará Kant en el § 47: "El genio no puede proporcionar más que rico material para productos del arte bello; la elaboración de ése y la forma exigen un talento formado por la academia, para hacer de aquél un uso que pueda sostenerse ante la facultad de juzgar” (p. 219). Sin embargo, ¿cómo se reproduce ese producir? Kant no da luces sobre ello, y uno pudiera entonces suponer que la ficción ha sido suficiente para hacer emerger la figura del genio y su talento, pero no para determinar su replicabilidad. Christel Fricke (1998) sostiene: "Los artistas geniales extraen la regla de su trabajo de su genio y, por tanto, directamente de la naturaleza. Una regla de genio es completamente diferente de las reglas discursivo-conceptuales por las cuales la gente normalmente orienta sus actividades racionales" (p. 679) ${ }^{17}$.

Retomando el comentario de Desmond (1998), respecto de que en la figura del genio "la Ilustración debe gobernar al Romanticismo", todo indica que hay una continua zozobra de Kant para definir su estatus estético-trascendental; ambigüedad que acompañará su formulación definitiva en la tercera Crítica, donde inclusive se decretará que es imposible concebir al genio como productor del arte bello sin el concurso de la academia.

Tal zozobra, según pienso, representa una especie de antinomia en el entramado trascendental de la Crítica del juicio, que puede reflejarse en la contienda a propósito de la imposibilidad de determinar si en definitiva el arte forma parte del orden de la naturaleza o del de la libertad. El genio vendría a resolver esa suerte de hiato de la facultad de juzgar estética: naturaleza versus libertad o, si se prefiere, finalidad versus regla. Como lo expone Kant "Y, puesto que sin regla precedente jamás un producto podrá llamarse arte, tiene la naturaleza que dar la regla al arte en el sujeto (y a través del temple de las facultades de éste); es decir, el arte bello es sólo posible como producto del genio" (§ 46, p. 217).

Resumiendo: yo sugeriría, a falta de una mejor explicación ontológica o trascendental, que el genio de Kant debe entenderse como una invención de la tercera Crítica puesta en escena a fin de satisfacer 'por dentro' las

\footnotetext{
17 "Geniale Kunstschaffende schöpfen die Regel ihres Schaffens aus ihrem Genie und damit direkt aus der Natur. Von den diskursiv-begrifflichen Regeln, an denen Menschen ihre vernünftigen Tätigkeiten normalerweise orientieren, ist eine Regel des Genies völlig verschieden”.
} 
expectativas de puente que él mismo tejió respecto de la Crítica del juicio, en su tarea de conectar razón pura teórica y razón pura práctica. En este caso, y en particular sobre un aspecto políticamente tan sensible para la época como el arte bello, el genio intentará, desde la más pura esfera de la ficción, unir la propiedad racional de la idea estética con la facultad estético/práctica de la producción de la obra.

\section{Conclusiones}

La tercera Crítica ofrece un conjunto de ideas tan disímiles y contradictorias, que, dicho eufemísticamente, tornan incierto el paso final de la filosofía de Kant. La idea de ficción contenida en la Crítica del juicio, más que un mero recurso de la doctrina del método, parece reflejar la zozobra de un Kant que intenta mostrar una estructura racional formal unitaria, pero que consta de varios usos irreconciliables (Labrador, 2018). Esta sería la razón por la que el filósofo prusiano se ve obligado a recurrir a la ficción del como si, en el sentido de forzar arquitectónicamente la relación epistémico-estética del sujeto con una presunta finalidad de las cosas (¿cómo entonces explicar que la mitad de la fundamentación estética esté en la primera Crítica, como estética trascendental, y la otra mitad, esparcida en toda la primera parte de la tercera Crítica?). Aneja, también, la ficción que viene a completar la epistemología de la primera Crítica mediante la idea del intelecto arquetípico como organizador del mundo en la crítica teleológica. En el caso del genio el argumento se repite, pero en una dirección distinta. Kant requiere de este extraño talento original para cautelar que no queden del todo abiertas las puertas a la irrupción del Romanticismo, particularmente en su versión irracional; cuestión que haría tambalear no solo su estética filosófica, sino muy esperablemente toda su crítica a la metafísica de Wolff. Todo esto, mientras "espera terminar su Crítica del gusto hacia Pascua en manuscrito, aunque la impresión tardará más” (Kant, 1912).

\section{Referencias}

Álvarez, W. (2017). Técnica y conformidad a fin en la estética kantiana. Praxis Filosófica, 45, pp. 29-55. http://www.scielo.org.co/pdf/pafi/ n45/2389-9387-pafi-45-00029.pdf

Besançon, A. (2006). La iconoclasia moderna. Actas del V Simposio Internacional Fe cristiana y cultura contemporánea "Cristianismo en una cultura postsecular” (pp. 217-225). Pamplona: Eunsa. 
Brandt, R. (2006). La cuarta Crítica de Kant. Azafea, 8, pp. 181-208. https:// doi.org/ 10.14201/632

Costa, I. (2018). La ficción en Platón. Síntesis. Revista de Filosofía, 1 (2), pp. 12-30. https://doi.org/10.15691/0718-5448Vol1Iss2a241

Derrida, J. (2001). La verdad en pintura. Buenos Aires / Barcelona: Paidós.

Desmond, W. (1998). Kant and the Terror of Genius: Between Enlightenment and Romanticism. H. Parret (Ed.), Kants Ästhetik (pp. 594-614). Berlin / New York: Walter de Gruyter.

Dickie, G. (2003). El siglo del gusto. Madrid: Machado.

Dumouchel, D. (1998). Genèse de la Troisième Critique: le rôle de l'esthétique dans l'achèvement du système critique. H. Parret (Ed.), Kants Ästhetik (pp. 18-40). Berlin / New York: Walter de Gruyter.

Ertene, M. (2012). Reconsidering the Kantian Concept of Genius through the Questions of Nature, Freedom and Creativity (Master of Arts Thesis). Ankara: Middle East Technical University. http://etd.lib.metu.edu.tr/ upload/12615050/index.pdf

Falgueras, I. (1999). Perplejidad y filosofía trascendental en Kant. Cuadernos de Anuario Filosófico, 71, pp. 5-164. https://dadun.unav.edu/ bitstream/10171/6007/1/71.pdf

Fricke, C. (1998). Kants Theorie der schönen Kunst. H. Parret (Ed.), Kants Ästhetik (pp. 674-689). Berlin / New York: Walter de Gruyter.

Grondin, J. (2000). La actualidad de La religión dentro de los límites de la mera razón de Kant. Ideas y Valores, 113, pp. 80-85. https://tinyurl. $\mathrm{com} / \mathrm{y} 44 \mathrm{hv} 5 \mathrm{cv}$

Johnson, R. (2011). Locating the Abject in the Third Critique. Consciousness, Literature \& the Arts, 12 (2), pp. 1-58. http://www.dmd27.org/ ryanjohnson.html

Kant, I. (1912). Briefwechsel (H. E. Fischer, Hrsg.). München: Georg Müller.

Kant, I. (1992). Crítica de la facultad de juzgar (P. Oyarzún, Trad.). Caracas: Monte Ávila. 
Kant, I. (1998). Crítica de la razón pura (P. Rivas, Trad.). Madrid: Alfaguara.

Kant, I. (2005). Correspondencia (M. Torrevejano, Ed. y Trad.). Zaragoza: Institución Fernando el Católico.

Körner, S. (1977). Kant. Madrid: Alianza.

Labrador, D. (2018). Sobre la división de la razón en Kant: la ruptura con el sistema de racionalidad absoluta. Revista de Humanidades de Valparaiso, 6 (11), pp. 39-74. http://dx.doi.org/10.22370/rhv.2018.11.854

Lories, D. (1998). Génie et goût: complicité ou conflit? Autour du Par. 50 de la Troisième Critique. H. Parret (Ed.), Kants Ästhetik (pp. 564-593). Berlin / New York: Walter de Gruyter.

Marqués, A. (1998). Reflection and Fiction in Kant's Aesthetics. H. Parret (Ed.), Kants Ästhetik (pp. 219-228). Berlin / New York: Walter de Gruyter.

Martynova, S. (2020). Kant's Teleology and the Problems of Bioethics. ConTextos Kantianos, 11, pp. 37-54. https://doi.org/10.5281/zenodo.3865130

Philonenko, A. (1998). L'architectonique de la Critique de la faculté de juger. H. Parret (Ed.), Kants Ästhetik (pp. 41-52). Berlin / New York: Walter de Gruyter.

Platón. (2000a). Diálogos IV. República (C. Eggers, Trad.). Madrid: Gredos.

Platón. (2000b). Diálogos VI. Filebo, Timeo, Critias (Á. Durán y F. Lisi, Trads.). Madrid: Gredos.

Pringe, H. (2013). La afección como ficción y el idealismo trascendental. Perspectiva Filosófica, 1 (39), pp. 2-9. https://ri.conicet.gov.ar/ handle/11336/28946

Vaihinger, H. (2013). Die Philosophie des Als Ob. Bremen: Salzwasser-Verlag $\mathrm{GmbH}$. 